\title{
Intrahepatic Bile Duct Cancer by AJCC v8 Stage
}

National Cancer Institute

\section{Source}

National Cancer Institute. Intrahepatic Bile Duct Cancer by A/CC v8 Stage. NCI Thesaurus.

Code C134604.

A term that refers to the staging of intrahepatic bile duct cancer according to the American Joint Committee on Cancer, 8th edition. This staging system applies to intrahepatic cholangiocarcinomas, combined hepatocellular-cholangiocarcinomas (mixed hepatocholang iocarcinomas), and primary neuroendocrine tumors of the liver. Primary sarcomas of the liver, pure hepatocellular carcinomas, hilar cholangiocarcinomas, and gallbladder carcinomas are not staged using this staging system. (from AJCC 8th Ed.) 